\title{
Acceptability of Just-in-Time Teaching amongst medical students: A pilot study
}

\author{
Somsubhra De ${ }^{1}$, Nagandla Kavitha ${ }^{2}$, Sachchithanantham Kanagasabai \\ ${ }^{1}$ Department of Obstetrics \& Gynecology, Melaka Manipal Medical College, Melaka, Malaysia. ${ }^{2}$ International \\ Medical University, Jalan Rasah, 70300 Seremban, Negeri Sembilan, Malaysia.
}

$\begin{array}{ll}\text { ARTICLE INFO } \\ \text { Received } & : 23 / 05 / 2013 \\ \text { Accepted } & : 18 / 08 / 2013 \\ \text { Published } & : 09 / 03 / 2014\end{array}$

\section{KEYWORD}

Just-in-time-teaching

Acceptability

Perceptions

Teaching

Learning

Medical students

\section{ABSTRACT}

Introduction: Just-in-Time Teaching (JiTT) is a novel method of teachinglearning used in various disciplines of science and humanities. It is a technique that scaffolds the students learning process by reducing the cognitive load which is the load related to the executive control of working memory. Just in time teaching underpins the concept that expertise in learning originates from the knowledge already stored in long term memory and with subsequent interaction between the learner and teacher motivates enhanced active learning and optimizes the intellectual performance. Objective: The objective of the study is to assess the acceptability of JiTT over traditional lecture teaching among the medical students. Method: In a cross sectional pilot study, three hundred thirty five students participated in a questionnaire based study that grades the various aspects of the traditional lecture series. After the implementation of JiTT method for a period of four months, three hundred two students completed the questionnaire, grading the same variables for JiTT. The analysis was done by using SPSS version 11 applying Paired t test and McNemar's Test. Result: The results of our study highlighted that JiTT technique was perceived superior to traditional teaching with statistically significant outcomes in the clarity of the topic $(p=0.003$, ) duration of the session $(p=0.002)$, knowledge gained and orientation for exams $(\mathrm{p}=0.044)$. The students perceived JiTT method as less monotonous $(\mathrm{p}=0.005)$ increasing their alertness during these sessions $(p=0.002)$. Conclusion: We therefore propose that Just-in-Time Teaching method is a more interactive and acceptable teaching-learning tool shifting the nature of teaching to a more student-centric approach as perceived by the medical students. This is the first pioneer study on JiTT to be performed on undergraduate medical students so far.

(C) Medical Education Department, School of Medical Sciences, Universiti Sains Malaysia. All rights reserved.

CORRESPONDING AUTHOR: Nagandla Kavitha, International Medical University, Jalan Rasah, 70300, Seremban, Negeri Sembilan, Malaysia. Email: kavitha.nagandla@gmail.com

\section{Introduction}

The concept of Just-in-Time Teaching (JiTT) was pioneered by Gregor Novak who was a professor of physics. He found that the students, who had little interest in a subject or perhaps feared the subject, also enjoyed learning when they were truly engaged (1). The concept was to make students more participatory. The students were given pre-class web-based assignments such as power point slides with questions a day prior to the scheduled lecture. This concept encourages students to prepare ahead of time, the night before, thereby increasing the chances of creating preliminary long-term memories. This preparation of the responses or 
answers to those questions just prior to their class is considered 'just in time'. The faculty reviews the answers during the session and can tailor the discussion to the specific needs of the students. This exercise encourages the students to be well prepared for their classes and also motivated them for active learning and reducing the cognitive load. Cognitive load is the load related to the executive control of working memory. Extraneous cognitive load is the load imposed by the poor format of instructions delivered to the students that increases the visual split attention resulting in poor student performance. Just-in-Time Teaching (JiTT) provides the necessary supportive information prior to task and prerequisite information at the time of task that reduces the extraneous cognitive load thereby avoiding the split attention effect and effectively increases the working memory for reasoning and comprehension (2). The linking of out-of-class activities of the students with the classroom activities also gives the opportunity to the faculty to identify the gaps in the conceptual understanding of the students and therefore to specifically address them.

JiTT method has been analyzed in various disciplines of science and humanities (3). It stressed on active student participation in the learning process. It has been found to have a good impact on the learning outcomes and also enhanced in-class teaching efficiency and effectiveness. However extensive literature search did not reveal any analysis of this method or its comparison with traditional lectures in this context for medical students.

Our objective in this pilot study is to compare the perception of JiTT method of teaching and traditional lectures amongst medical students. The focus in this study is to evaluate the perception of the medical students about the technical and implementation aspects of Just-inTime Teaching and traditional lectures by a questionnaire survey using Likert scale and to compare and analyze the differences in their perception thereby determining the acceptability of JiTT as a teaching tool.

\section{Method}

This study was conducted in the department of Obstetrics and Gynecology in a reputed private medical college over a period of four months between October 2011 and January 2012. A total number of 335 students voluntarily participated in this study, which was in a questionnaire survey format. The questionnaire included the demographic profiles, various technical and implementation aspects of teaching-learning methods rating them using Likert scale.

The medical students were given the questionnaire to grade the various technical and implementation aspects of the traditional lectures that also served as pre-test data for our study. Subsequently JiTT method was implemented for the next twelve lecture topics.

\section{How was JiTT designed?}

For the next twelve topics the students were emailed web-based power point slides with questionnaire as assignments a day prior to the scheduled, by the faculty in charge. The sessions included topics from high risk obstetrics (Hypertension in pregnancy, Diabetes in pregnancy, Multifetal pregnancies and Antepartum hemorrhage), gynecological malignancies (Cervical cancer, Ovarian cancer and Uterine cancer), reproductive medicine (Physiology of menstrual cycle, Subfertility and PCOS) and labor (Normal labor and Breech). The students completed their questionnaire assignments that served as warm up questions, to be covered in the upcoming class room teaching session. The students prepared the answers to the questions from the material on the web for the class. The faculty in the class room used student responses to create an interactive classroom environment. The faculty graded the warm up assignment that increased the alertness of the students and encourages active participation.

After implementing this method over four months, another questionnaire survey was done and the students were asked to grade the various technical and implementation aspects of the Justin-Time Teaching method. The questionnaires 
with incomplete data were excluded from analysis. The anonymity of the students was maintained as they were coded with an alphanumeric code. Statistical analysis was done by SPSS version 11 applying paired $t$ test and McNemar's test to analyze and compare the differences in the students' perception. This study was approved by the Research and Ethical committee of the college.

\section{Result}

A total of 302 completed questionnaires were analyzed in this study. The average age of the students was 23.15 years $(\mathrm{SE}=0.07)$. There were 185 females (61\%) and 117 males (39\%) students. The academic background of the students was reflected from the fact that 209 (69\%) students had their course funded by scholarship and 256 (85\%) students have never failed their semester exams. Total of 289 (96\%) students interacted in some form of social networking websites therefore implying that they were well versed with the use of internet.

Figure 1 depicts the comparison of perception based on the technical issues. The difference of perception reached statistical significance in clarity of the method, duration of the session and the knowledge gained being relevant for exams.

Figure 2 depicts the comparison of perception based on the implementation issues. The difference of perception reached statistical significance only in alertness to the session. However, this was expected because Just-inTime Teaching was focused on interaction between students and their lecturers and grading of their assignments respectively. The difference in other areas like application (how it was done), comprehension, motivation and the style of presentation of facts were not statistically significant.

Figure 3 depicts the comparison of general perception. This section was formatted in YesNo answers. Significant number of students felt JiTT was less monotonous and there was noticeable increase in alertness during the sessions.

\section{Discussion}

Just-in-Time Teaching is a pedagogical system that improves learning. This teaching method has been used in various disciplines like physics, biology, chemistry, mathematics, sociology and writing (4). In another study, teaching geography by this method has shown to improve the student's performance in classes (5). Many businesses use this method to make the work process more flexible and responsive (6). Based on the decades of research on the undergraduate teaching experience, Chickering et al, created the 'Seven Principles of Good Practice in Undergraduate Education' in 1987 that became the major resource for teaching and learning in higher education.

Table 1: Good practice principles of undergraduate higher education (7).

\begin{tabular}{ll}
\hline 1. & $\begin{array}{l}\text { Encourages contacts between students and } \\
\text { faculty }\end{array}$ \\
2. Develops reciprocity and cooperation among \\
students \\
3. Uses active learning techniques \\
4. \\
5. Emes prompt feedback \\
6. Communizes time on task \\
7. Respects diverse talents and ways of learning \\
\hline
\end{tabular}

How does JiTT justify the teaching principles?

As identified by Alexander Astin, the three critical factors for students' success in higher education include (1) Student-Student interaction, (2) Student-faculty interaction, and (3) Time on task (8). Just-in-Time Teaching achieves these three teaching principles. Besides these, it created team spirit among the students as they work towards the objective of orienting themselves for the exams with maximum retention of knowledge. The out of class room assignments potentiates their learning benefit. Apart from the classroom teaching, the faculty 'communicates' with their students and based on the students' responses, they find the lacuna in their conceptual or factual understanding.

A JiTT classroom has therefore a high level of interaction between the students and faculty via the warm up assignments and class room 
learning exercises. The current research on new learning depends on the learner's prior knowledge in concordance with the current state of understanding as indicated by Bransford et al. (9). If the initial understanding is not engaged, it may result in failure to grasp new concepts that are taught in classroom settings and the student may remain with the preconceptions/ misconceptions outside the classroom. This theory of 'constructivism' emphasizes that new concepts are best learned in the class room when the teacher addresses the prior knowledge that transpires to uncover the misconceptions that the students bring to class with them.

Mestre and Cocking believed that formative assessment which is the feedback provided during learning is largely missing in traditional lecture classes (10). This feedback gives opportunity for the students to improvise their thinking process and prepare them with concepts essential for their summative assessment. One of the fundamental advantages of Just-in-Time Teaching is the specific feedback that enhances the active learning skills of the students, that promotes engagement of the students in the class as demonstrated in our study by increased alertness. Thus JiTT addresses the other two principles of teaching which are active learning and prompt feedback.

By this method, the teaching becomes a two-way process, with students being in the main focus and at the same time the faculty member is more aware of the student's strong and weak areas in the subjects (11). Just-in-Time Teaching also throws light on the fact that students are more successful if they study a subject frequently in sessions of moderate length rather than infrequent yet lengthy sessions (12). Studies have shown that students learn best when they actively engaged rather than just being passive (13).

\section{Starting Point in JiTT}

\section{Pre lecture Resources - Warm up Question assignments - Outside Class room - Web based \\ How does this help? Identifies the students prior knowledge, belief and misconceptions<smiles>C1CCCCC1</smiles>

\section{Warm up responses}

Faculty analyses the responses just before class time: so they are Just in Time to clarify the concepts in the class<smiles>C1CCCCC1</smiles>

\section{Interactive lecture in the class room by the faculty}

Fosters active and cooperative learning among students 


\section{What is not JiTT?}

It is paramount not to confuse JiTT with E learning or Distance learning (DL) or Computer - aided instruction (CAI) as it uses Web Technology. The crux is the presence of human instructor and with the combination of web learning that enhance the interaction between the teacher and students.

\section{Reflections}

The results of the study revealed that medical students perceived JiTT as superior in terms of clarity of topic and knowledge gained. Having a baseline of the facts that are unknown determines focused learning. To get started on that, the students need assessment of their preexisting knowledge and competence. The warm up question assignment serves as start point and the opportunity to receive feedback provides the chance for the students to reflect on what they have learned and what they still need to know.

This is supported in literature as evidenced by Kelli M. Slunt et al in 2004 in his study comparing the lecture based teaching chemistry class teaching with JiTT and reported that JiTT approach of student centered learning had a greater impact on students' performance and participation (14). As stated by Scott et al, a conceptual change needs to be fostered eminently in science as particularly, learning here is an accumulation of new knowledge and change of existing knowledge (15).

The students perceived that JiTT technique made them better oriented for exams. However with regards to application and motivation there was no significant difference. This is of concern as it can be probably related to the study habits of the students. Cramming' is a onetime intensive study session some students practice prior to the exams that saturates the short-term memory which is not an efficient way to retain knowledge. In a survey by Simkins et al, exploring what students do actually while preparing for JiTT exercises, the problem of sharing answers by the students was identified thereby not enough efforts by the students and hence no gains from the exercises was observed. It was also brought to light that students demonstrated distorted understanding on the efforts required for the preparation of the JiTT exercises. The students with the habit of cramming that worked for them earlier were reluctant for these frequent JiTT exercises there by producing negative feedback loop (16). This calls for the need for effective motivation of the students that can be addressed by looking at affective aspects of the learning that plays a role in the success or failure of any pedagogical innovations. Svinicki in 2005 advised an approach to deal with the affective dimension that involves the five key principles: 1.Show interest in and support the mistakes 2.Providing opportunities for multiple attempts without penalizing 3.Providing model for the best way to learn 4. Provide credit points for progress 5.Creating a community helping each other to help (17). The fact that needs to be emphasized is the need for the faculty to orient the students prior to the initiation of the JiTT providing explicit information about the expectations and address the concerns of the students.

\section{Does JiTT increase the faculty work load?}

It is to be noted that by using JiTT the workload of faculty is not reduced but it becomes more intense. With the busy work schedule of the faculty juggling between teaching and research, there is little time to endow on modifying the teaching process. However, as suggested by Kathleen A Marrs and Novak, the faculty can incorporate any of the aspects of JiTT to meet their own course needs thereby utilizing the additional time needed (18). 


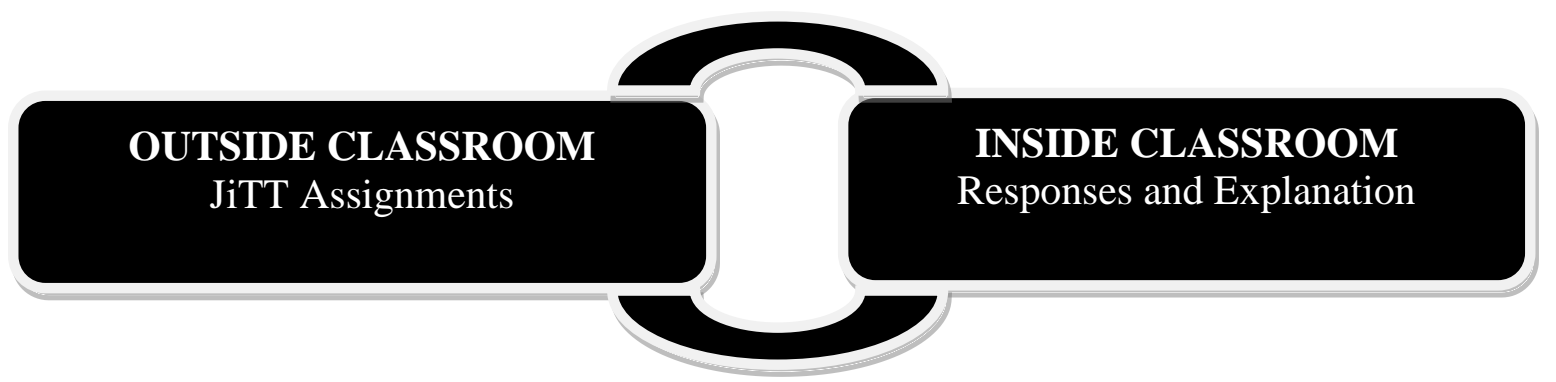

JiTT: Concept of blended active learning with Web Technology Feedback Loop: Linking the classroom with learning environment of the students and learning from class form the basis for subsequent assignments

The web based assignments gives the opportunity to identify the large body of preexisting knowledge of the students that serves as platform for the faculty to modify the teaching process. It is proven that these interactive sessions in JiTT greatly improve the student's attendance in comparison with traditional lectures (20). Thus the extra time involved in facilitating JiTT is a rewarding experience for the faculty as they are using the pedagogical strategies that are the recommendations by the National science foundation for effective undergraduate teaching (19).

\section{Conclusion}

The current literature clearly projects JiTT as an outstanding pedagogical tool in which the teaching becomes two-way process with students being in the main focus and at the same time the faculty member is more aware of the student's strong and weak areas in the subjects. It is evident from our study that the mean scores of various aspects of JiTT which were all higher than traditional lectures. Even though JiTT has been studied in various disciplines the data about its application in medical sciences is sparse (4). Our attempt was to compare the perception of the medical students about the new method with the traditional method. The results of our study project that the students perceived JiTT as more superior to traditional teaching in the view of the orientation of exam, but in terms of application and motivation there was no statistical significance reached. This reflects the need to address the students concern effectively and make changes to the methodology and content delivery that suit the needs of the students in the local context. Many would sight similarity with problem based learning but JiTT is more flexible and universal whether it is a small group teaching or a big lecture audience. JiTT increases the assessment scores as evident in the outgoing GPA results of US Air Force Academy students (11). Hence a further step to evaluate the difference in the assessment scores in the medical schools after implementing JiTT would determine the efficacy of JiTT in a much more objective platform for medical students. The possible limitation of this study is that perception has an element of subjectivity which might influence the students while answering the questionnaire survey.

In conclusion, as the medical students are entering their medical schools with heterogeneity of their educational background and aptitudes, JITT is a relevant method for today's comprehensive and integrated curriculum. JiTT is more interactive and acceptable teachinglearning tool as perceived by the medical students compared to traditional lecture sessions. However, to change the method from traditional lectures to JiTT in medical schools, multi-centric studies with bigger and diverse student population needs to be done in view of its potential as a more favorable and feasible teaching tool and also educational outcomes need to be compared amongst these groups. 


\section{Acknowledgement}

We would like to thank Dr Ankur Barua, Dr Abby Choke, Dr Jun Han Lai, Dr Simon Chen and Dr Lyon Hyoung for their efforts and help in statistical support and retrieving the data for this study.

\section{Reference}

1. William Rozycki. Just-in-Time Teaching. Research \& Creative Activity:Indiana University; XXII (1),1999:

2. Sweller, J. (1988). "Cognitive load during problem solving: Effects on learning". Cognitive Science 12 (2), 257-285

3. Claude Cookman, Middendorf, J., \& Pace, D. Using JiTT to foster active learning in a humanities course. Just-in-Time Teaching in History. In S. Simkins \& M. Maier (eds.), Just in-Time Teaching Across the Disciplines and Across the Academy. Sterling, VA: Stylus.

4. A. Gavrin, Jeffrey X. Watt, Kathleen Marrs, Robert E. Blake, Jr. Just-in-Time Teaching (JiTT): Using the Web to Enhance Classroom Learning. Proceedings of the American society for Engineering Education Annual conference and Exposition, 2003.

5. Luo W. Just-in-Time Teaching (JiTT) improves students' performance in classes adaptation of JiTT in four geography courses: Journal of Geoscience Education, 56(2), 166-171.

6. Monden, Y. An Integrated Approach to JustIn-Time: Toyota Production System, Inst of Industrial Engineers, Norcross, GA;1998

7. Chickering, A.W., and Gamson, Z.F. (March 1987). Seven principles for good practice in undergraduate education. AAHE Bull. 37.http://aahebulletin.com/public/archi ve/sevenprinciples1987.asp(accessed November 15, 2003.

8. Astin, A.W. What Matters in College? Four Critical Years Revisited. New York: JosseyBass, 1993.

9. Bransford, John; Brown, Ann L. and Cocking, Rodney R. How People Learn: Brain, Mind, Experience, and School: Expanded Edition, National Research Council (U. S.) Committee on Learning Research and Educational Practice, National Academies Press, 2000.

10. Mestre, J., \& Cocking, R. R. Applying the science of learning to the education of prospective science teachers. In: Learning
Science and the Science of Learning: Science Educators' Essay Collection, ed. R. W. Bybee, Arlington, VA: National Science Teachers Association Press, 2002.

11. Felder, R. M. G. N. Felder, and E. J. Dietz. A Longitudinal Study of Engineering Student Performance and Retention. V. Comparisons with Traditionally-taught Students: Journal of Engineering Education, 1998; 87(4), 469-480.

12. Dempster, F. N and Farris, R. The Spacing Effect: Research and Practice. Journal of Research \& Development in Education, 1990; 23(2), 97-101.

13. Godfrey, R C. Undergraduate examinations-A continuing tyranny: The Lancet, 1995; 345, 8952; 765.

14. Kelli M. Slunt, and Leanna C. Giancarlo. Student-Centered Learning: A Comparison of Two Different Methods of Instruction: Journal of Chemical Education, 2004; 81(7) 985-988.

15. Scott, P., Asoko, H., \& Driver, R. Teaching for conceptual change: A review of strategies. In R. Duit, F. Goldberg \& H. Niedderer (Eds.), Research in Physics Learning: Theoretical Issues and Empirical Studies (pp. 310-329), 1992.

16. Simkins, Scott and Maier, Mark. Using Justin-Time Teaching Techniques in the Principles of Economics Course: Social Science Computer Review, 2004; 22 (4), 444-456.

17. Hake, R. Interactive-engagement versus tradition methods: a six-thousand-student survey of mechanics test data for introductory physics courses: Am. J. Physics, 1998; 66(1), 64-74.

18. Marrs, Kathleen A., and Novak, Gregor M. Just-in-Time Teaching in Biology: Creating an Active Learner Classroom Using the Internet: Cell Biology Education, 2004; 3 (1), 49-61

19. National Science Foundation Advisory Committee to the Directorate for Education and Human Resources (NSF-AC) Shaping the Future: New Expectations for Undergraduate Education in Science, Mathematics, Engineering, and Technology. Arlington, VA: National Science Foundation, 1996.

20. Gregor M. Novak, Evelyn. T. Patterson. A. Gavrin and R. C. Enger. Just-in-Time Teaching: active learner pedagogy with www. Paper presented at IASTED International Conference on Computers and Advanced Technology in Education. May 27 
-30, in Cancun, Mexico, http://webphysics.iupui.edu/introphysics.

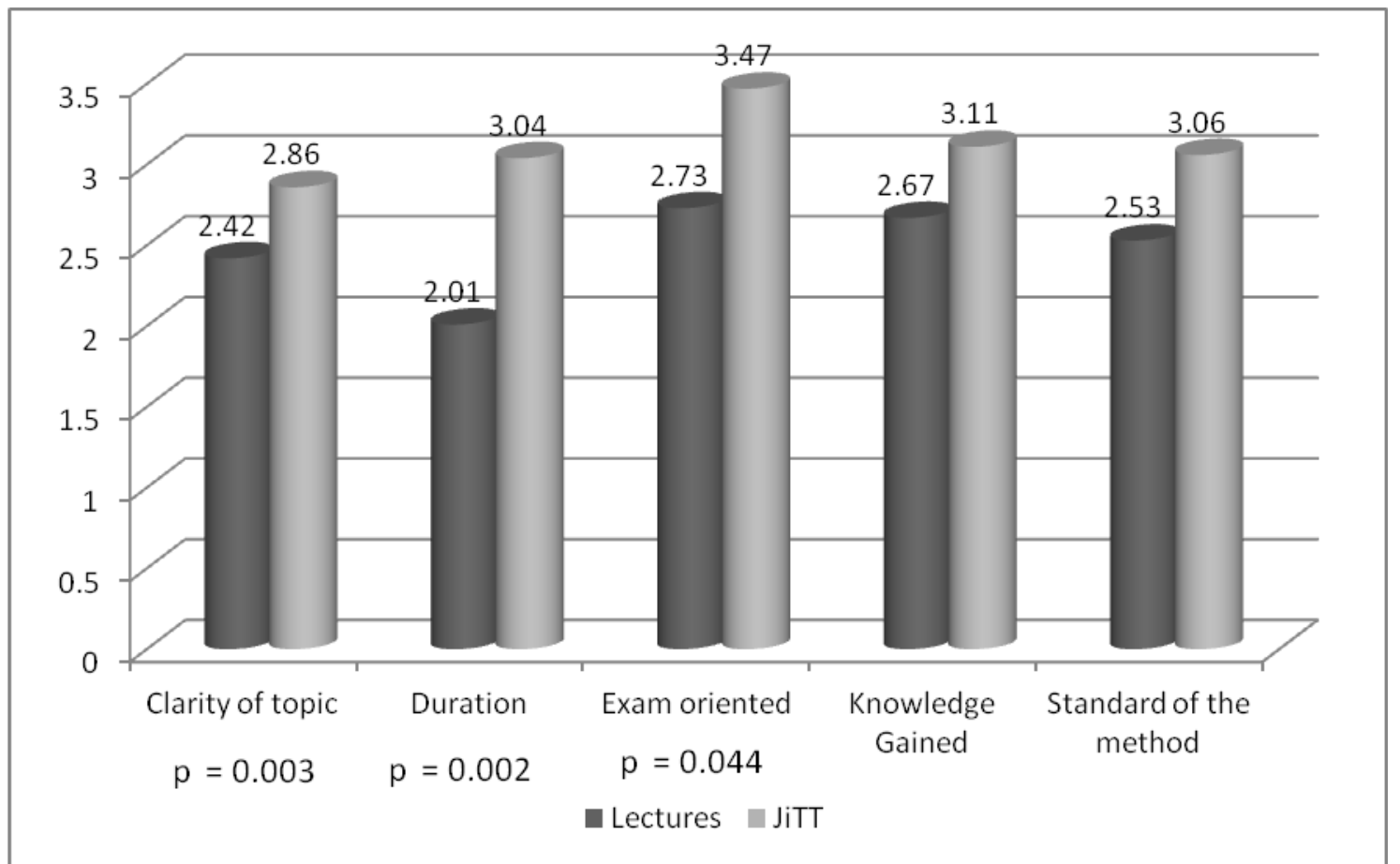

Figure 1 Comparison of perceptions based on the Technical aspects of the methods

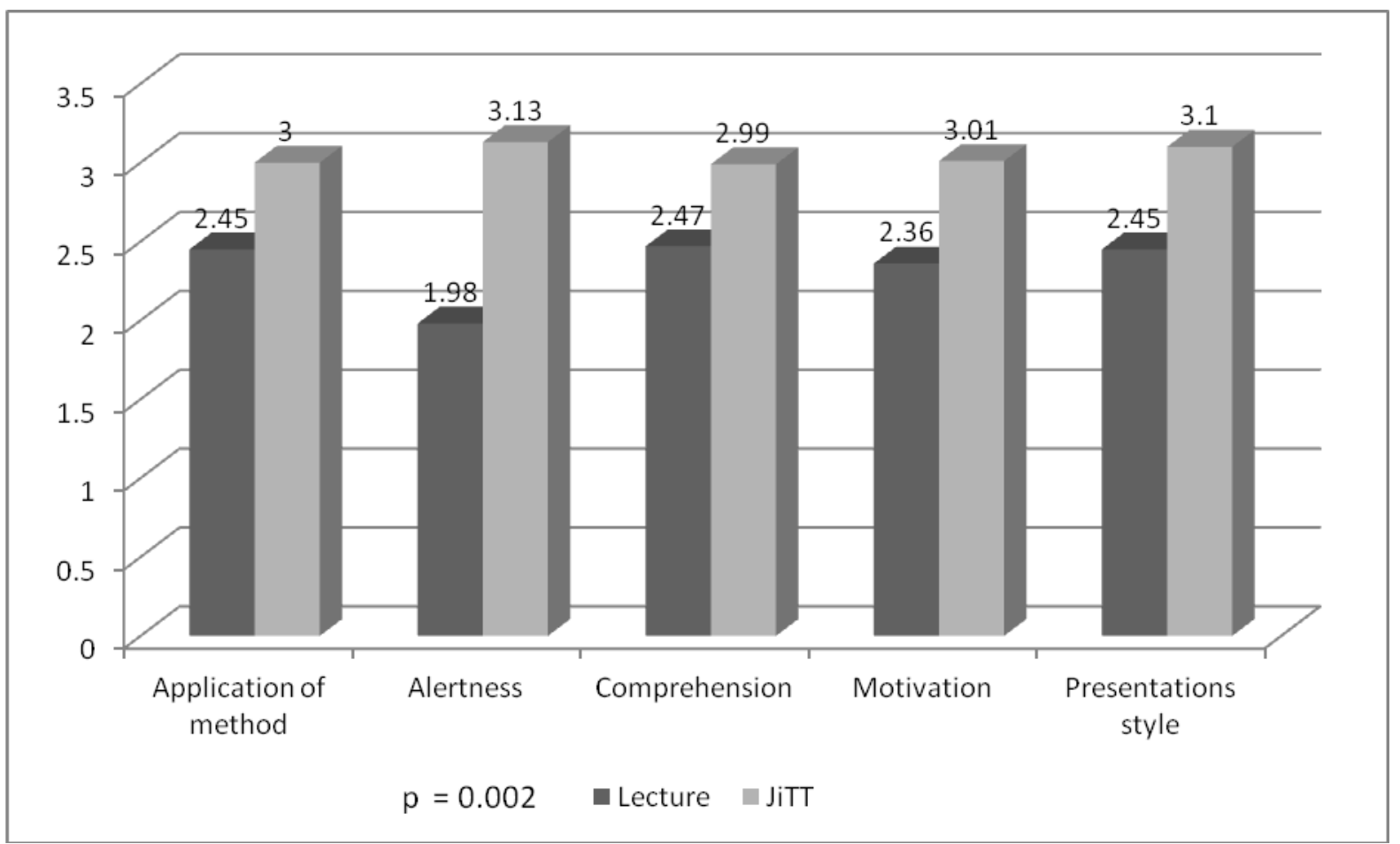

Figure 2 Comparison of perceptions based on the Implementation aspects of the methods 


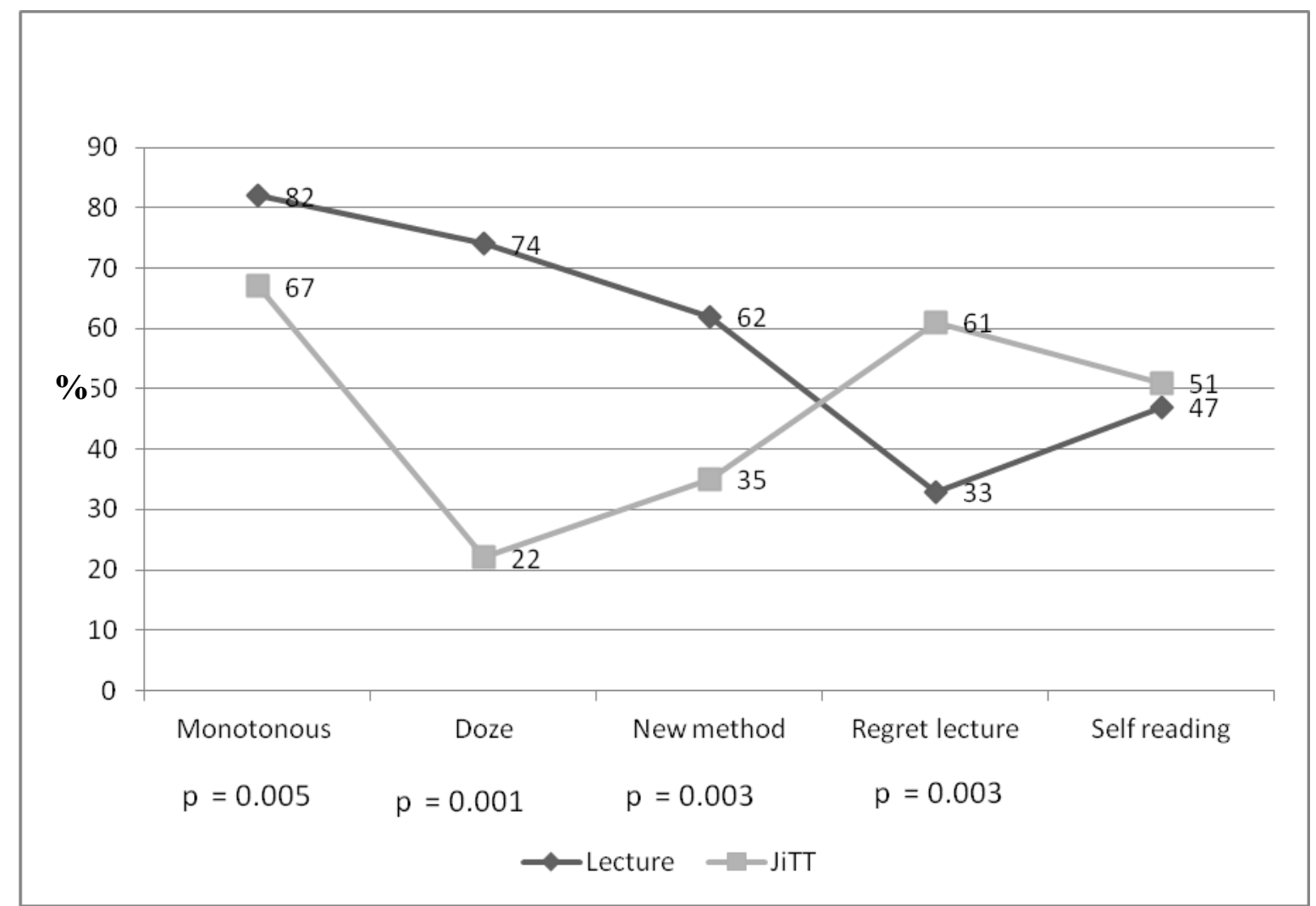

Figure 3 Comparison of perceptions based on the General aspects of the methods 